\title{
Research on Interpenetration Between Solfeggio and Ear Training and Music Aesthetic Psychology Based on Aesthetics
} Dongbo Lin

\section{Fujian Vocational College of Art, Fuzhou, 350100, China}

\begin{abstract}
In the teaching of music major, solfeggio and ear training is widely recognized by the society due to its scientific, rigorous and logical property. In the teaching, as the teacher lacks of deep understanding of this discipline, the boring and tedious classroom teaching of practitioners easily makes students fail to really form good music aesthetics consciousness in learning and have poor imagination. In view of this, it is necessary to deeply study the interpenetration relationship between solfeggio and ear training and music aesthetic psychology based on aesthetics. In this paper, the necessity of studying solfeggio and ear training and music aesthetic psychology is analyzed and the interpenetration relationship between solfeggio and ear training and music aesthetic psychology is discussed.
\end{abstract}

Key words: Solfeggio and ear training; music aesthetic psychology; interpenetration; relationship

As the society develops continuously, the music works emerge constantly, embodying the diversity of China's arts. Music, dance and other art works bring profound influences to modern people's life. In any case, people's aesthetics is very important and sensation and acquiring beauty in life can better improve one's aesthetic ability. The solfeggio and ear training in the classroom teaching of music is closely related to the learners' aesthetic consciousness. The learners should comprehensively master the music rhythm, beat, melody and other knowledge and be closely combined with the modern people's life to enjoy the music. The learners can practically and effectively improve their music quality only by sensation the life in the complete music works and echoing with them.

\section{Necessity of studying solfeggio and ear training and music aesthetic psychology}

As solfeggio and ear training is the basic discipline of music, it has aesthetic features. Any music work is the close combination of rhythm, melody, form, style and various musical elements. To have historical style and aesthetics features, the music work must link with the social culture and aesthetic psychology. Solfeggio and ear training is deeply studied in the modern music aesthetic psychology theory, thus laying a theoretical foundation for the solfeggio and ear training education, providing more novel and unique research horizon and opening a new space for further studying music aesthetic psychology. Music aesthetic psychology formed by the cross-edge of many disciplines has rich knowledge content to provide a new perspective and multi-dimensional thinking form for the implementation of solfeggio and ear training. The learners of music can make an objective and fair evaluation according to the aesthetic features of the teaching of 
solfeggio and ear training course and carry out targeted training according to the music aesthetic psychology, such as music perception, memory, comprehension and other elements to reduce the blindness in the learning and get twofold results with half the effort. Of course, the comprehensive learning based on the music works can make learners deeply experience the musical forms with contemporary musical connotation and sense of beauty so as to better feel the artistic beauty of music.

\section{Interpenetration relationship between solfeggio and ear training and music aesthetic psychology}

\section{(I) Form music aesthetic perception}

Music aesthetic perception is the precondition of music aesthetic psychology and divided into simple sensation and complex perception. Sensation mainly means the feedback of the single attribute of a thing formed by the continuous processing of human brain information under the objective stimulation of sense organ. The sensation is the most primary form of cognition and mainly provides the fundamental material for perception and other complex understanding. In a similar way, music aesthetic sensation is the basis for the complex music aesthetic experience. For example, people must listen to the music in the form of direct perception in appreciating the music works though they cannot better understand and experience the tone, register, melody, harmony, style and mentality of music instantly. However, they can preliminarily perceive the charm of music to bring a sense of joy to modern people. The sense of joy is just on the sense organ level, but it is an important basis for music aesthetics. The primary physiological sensation is actually the premise of higher emotion and imagination. Solfeggio and ear training is also based on the primary physiological sensation and the above-mentioned perceptual basis has its own advantages in the specific teaching. For example, the beat and rhythm are the central link in the process of music rhythm practice, in which the tone, style, structure and other factors are combined for comprehensive training; however, the pitch, melody, emotion and other elements should be highlighted in solfeggio and the texture, harmony and structural analysis are the auxiliary factors of performance. With totality, selectivity, understanding and other basic features, perception is the comprehensive and overall control of things on the premise of sensation and a more positive and active psychological activity, and plays an important role. Sensation and perception are collectively called perception, for which the former is the basis of the latter and the latter is the deepening of the former and the two are associated with each other in the music aesthetics and jointly play a role. Therefore, the aesthetic perception is developed on the premise of sense perception: the things will affect the vision, hearing and other sense organs. Based on the stimulus of people's nervous system, the nerve stimulation is transmitted to the human brain so as to make people reflect on the thing's color and voice. Affected by the various labor and activities as well as complex social relations, the primary aesthetic perception is formed.

\section{(II) Form music aesthetic imagination}

With the existing music intention as the medium, music aesthetic imagination is the psychological process of listening to, memorizing and creating a new music, in which the perception of hearing organ is the important medium and the sensation of other organs also plays a significant role in the musical imagination. People don't regard all the voices as the medium, but actively choose the voices that are closely related to the situation and emotion to create to conduct selective memory. Association mainly refers to the psychological process of thinking of others from one thing. It is generally divided into association by similarity, association by contiguity, 
association by contrast and association by causation. In the daily aesthetic activities, the association by similarity and the association by contiguity are the most common. Association by similarity is mainly caused by the similarity in the process of association, that is, similarity of things in nature, mood, content and other aspects. The descriptive music in the music aesthetic activity is generally to imitate the tone color, level, speed and other aspects of voice so as to cause the modern people's imagination of life image and artistic conception. Association by contiguity is mainly caused by the proximity of various things in time and space. In the music aesthetic activity, the association is caused mainly by using voice to symbolize various things beyond voice or using voice to produce specific atmosphere to imply some things and objects. In the teaching of solfeggio and ear training, the important role of association cannot be neglected because it can not only improve the memory efficiency of melody and rhythm, but also practically and effectively help understand the emotional expression in the music works. Conception is one of the more complex psychological activities than association, which recombines the various perception imagery and memory imagery to produce a new imagery, that is, aesthetic intention, and can trigger deeper emotional experience. It is the most creative and imaginative new psychology activity. As music information is a kind of creative, non-natural, abstract, fuzzy and corresponding artistic form, the music creation, performance and appreciation need imagination. The high-quality music appreciation ability can promote the high-efficiency implementation of the teaching of solfeggio and ear training and the correct solfeggio and ear training is conducive to improve the artistic appreciation taste.

\section{(III) Form music aesthetic emotion}

Emotion mainly refers to people's attitude and experience of objective things to a certain degree in addition to cognition. People's attitude and experience of things are the reflection that the modern people's needs are satisfied. Generally, people have positive evaluation and form satisfactory and happy experience for the things that satisfy their needs and have negative evaluation and form unsatisfied and unhappy experience for things that do not satisfy their needs. In view of this, emotion is conducive to improve the cognitive activity and has special physiological change and external expression. From the perspective of object, different emotion has different object, thus causing the difference between content and orientation. The object of rational emotion is the relationship between people and objective world, which is embodied in the scientific research, with exploring the objective truth as the highest objective; the object of moral emotion is the interpersonal behavior relationship, which is embodied in the social relationship between people, with kindness as the highest rule; the main object of aesthetic emotion is the beauty and ugliness, sadness and joy in the life and art field, with beauty as the highest objective. From the perspective of the psychology of subject, the aesthetic emotion is different from other higher emotion to a certain degree. In the reaction process of rational emotion, thirst for knowledge, curiosity, interest and others will affect and even control the psychology of subject, for which the memory, thinking and other related region will be excited, but other regions may be restrained relatively, thus human mind will have a considerable distance between perceptual and rational after a long time. In the reaction process of moral emotion, people's main psychology may also be imprisoned or restrained by morality or form self-accusation by violating the moral injunction, thus forming psychological barrier. Therefore, in the reaction process of aesthetic emotion, people's perception, emotion and imagination will be harmonious to make the heart free. 


\section{(IV) Form music aesthetic comprehension}

In the aesthetic activity of modern people, the subject often directly grasps and understands the object connotation and aesthetic activity in a perceptual way, which is the aesthetic comprehension. It is the rational factor in the aesthetic activity and widely integrated into the perception, emotion and imagination process. The comprehension factors of music aesthetic experience mainly include the following levels: first, comprehension of the difference between actual state and illusory state, which distinguishes the event, plot, emotion and aesthetic attitude in the real life. In the music aesthetic activity, whether in creation, performance or appreciation, people should get into the role to share a common fate; however, people should not associate and even equalize the role emotion with the real emotion. The music sound is not concrete, so we can understand its intrinsic meaning only by relaying on imagination, association, emotion and other psychological activities. Therefore, the distinguishing of imaginary and real is very important for music aesthetic comprehension. Second, comprehension of the content of music works. Generally, the music works often have theme, plot, scene, model and other contents and for some of music works, the internal background, illusion and symbolic meaning should be deeply understood. As a kind of artistic form that the content is hidden in the form, the music is embodied mainly by a certain expression way and its clarity or fuzziness generally depends on the difference of music thinking, that is, the features of different music style in the music conception. Therefore, to deeply perform and appreciate certain music work, one must have the integrated aesthetic comprehension. Third, comprehension of the external form of music work. The aesthetic value of music art can be practically experienced only by deeply comprehending and mastering the external expression way of music art and mastering the content of music work based on the artistic form of music. The music form is a rigorous organic whole and uses melody, harmony, polyphony, musical form, composition and other means for integration, thus a unique form that others things do not have can be showed. Fourth, deep comprehension of the connotation of music work. The music works are often devoted to pursing the implication, thus forming the deepest comprehension of music work so as to make them show special artistic connotation in a meaningful form. The music works used in solfeggio and ear training also conform to these pursuits, which is conducive to expand the solfeggio and ear training and get better effects.

\section{Conclusion}

In conclusion, solfeggio and ear training can cultivate the music aesthetic psychology and improve the music aesthetic ability of learners. The true value of solfeggio and ear training is embodied in the teaching process to practically cultivate learners' aesthetic ability. The music aesthetic psychology integrates multiple disciplines and can provide multi-dimensional and multi-perspective thinking model for teaching of solfeggio and ear training. The study on the interpenetration between solfeggio and ear training and music aesthetic psychology provides good theoretical supports for the implementation and further development of solfeggio and ear training discipline. The music aesthetic psychology should run through the teaching of solfeggio and ear training to make the two keep pace with each other and realize the integration of the two based on aesthetics so as to form more diversified teaching system and comprehensively realize the perfect combination of humanistic spirit of art of literature and aesthetic art.

\section{References:}


[1] Liang Liqun. Cultivation of Aesthetic Consciousness in the Teaching of Solfeggio and Ear Training in Higher Normal Colleges[J]. Journal of Liaoning Educational Administration Institute, 2008 (25).

[2] Wang Aiguo. Enlightenment of Music Aesthetic Psychology on Music Aesthetic Education[J]. Journal of Shanxi University of Finance and Economics, 2009 (1).

[3] Huang Yi. On Manifestation of Music Aesthetics in Teaching of Solfeggio and Ear Training[J]. Art and Literature for the Masses, 2010 (23).

[4] Jiang Xue. Discussion on Situation of Music Aesthetic Psychology-—From Learning of solfeggio and Ear Training[J]. Songs Bimonthly, 2011 (4).

[5] Kong Guifen. Discussion on Teaching of Solfeggio and Ear Training Under the Perspective of Music Aesthetics[J]. The Grand State, 2012 (8).

[6] Xu Manman. Improvement of Students' Music Aesthetic Ability in Teaching of Solfeggio and Ear Training[J]. Journal of Chengdu University of Traditional Chinese Medicine (Educational Science Edition), 2014 (4). 